\title{
Urinary lithiasis - conventional open surgery
}

\author{
Participants: \\ iD Ernesto Reggio ${ }^{1}$ \\ Alexandre Danilovic ${ }^{1}$ \\ (iD) Antonio Silvinato ${ }^{1}$ \\ Wanderley Marques Bernardo²
}

1. Sociedade Brasileira de Urologia, São Paulo, SP, Brasil 2. Coordenador do Programa Diretrizes da Associação Medica Brasileira, São Paulo, SP, Brasil

Created on: September 2020

Contact:wmbernardo@usp.br

The Guidelines Project, an initiative of the Brazilian Medical Association, aims to combine information from the medical field in order to standardize producers to assist the reasoning and decision-making of doctors.

The information provided through this project must be assessed and criticized by the physician responsible for the conduct that will be adopted, depending on the conditions and the clinical status of each patient.

Open surgery for urolithiasis has been replaced by minimally invasive alternative techniques. The purpose of this Guideline is to present doctors, specialists, and healthcare institutions with recommendations that may assist in the decision-making regarding patients whose one of the treatment options for Urolithiasis is open surgery. A systematic review of the literature was performed, without time restrictions, in the Medline database, retrieving 4,457 papers, of which 19 were selected to answer the clinical question: What are the main indications for open surgery in urolithiasis? The details about our methodology and results are presented in Annex I.

\section{INTRODUCTION}

Open surgery for urolithiasis, once considered the gold standard for most symptomatic calculi, has been overwhelmingly replaced by minimally invasive alternative techniques, including extracorporeal shock wave lithotripsy (ECWL), ureterorenoscopy (URS), and percutaneous nephrolithotomy (PNL).

ECWL, described for the first time in 1980, quickly became one of the most common alternatives to open surgery for calculi ${ }^{12}$. Although the success rates vary, depending on specific factors of the calculi and the patient, the stone-free rates can exceed $90 \%$ in appropriately selected patients ${ }^{3}$.

Ureterorenoscopy has also been increasingly used to treat calculi and is the fastest-growing endourological procedure for this purpose ${ }^{4}$. The success rates for treating ureteral calculi are very high, with calculus-free rates $>94 \%$ when ureteroscopes are used to treat distal ureteral calculi and $>95 \%$ when flexible endoscopes are used for treating proximal ureteral calculi ${ }^{5}$.

PNL is the most appropriate minimally invasive technique for larger and more complex calculi. Soucey et al. (2009) obtained an average calculus-free rate of $78 \%$ immediately after the PNL in $>500$ patients with 
complete or partial staghorn calculi, but at the threemonth follow-up, the calculus-free rate improved to $91 \%$.

\section{RESULTS}

\section{Open surgery in adult patients}

Laparoscopic and robotic procedures are conceptually more similar to the open surgical methods than to the minimally invasive techniques but can achieve their goals with smaller incisions, less tissue manipulation, as well as with a faster recovery time than open surgery. However, they require the availability of equipment and surgeons trained in robotic laparoscopy or robotics ${ }^{3}(\mathrm{D})$.

The Guidelines of the American Urological Association (AUA) consider the indications for laparoscopic/ open/robotic surgeries to be rare and limited and deem these techniques more effective for removing large or complex calculi, particularly in patients with anatomic abnormalities of the gastrointestinal tract, especially those that require reconstruction, as in the case of ureteropelvic junction (UPJ) or concomitant ureteral stenosis ${ }^{4}(D)$. Previous guidelines (2005) by the AUA considered excessive morbid obesity or an extremely poor function of the affected renal unit indications for open surgery ${ }^{5}(\mathrm{D})$.

In the guidelines of the European Association of Urology (UAE), there is a consensus that most complex calculi, including partial and complete staghorn calculi, should be addressed primarily using PNL or a combination of PNL and ECWL. However, if a reasonable number of percutaneous approaches is not successful, or if multiple endourological approaches were tried without success, laparoscopic or open surgery can be a valid option for primary treatment ${ }^{6}(D)$.

Previous guidelines by the UAE (2012) indicated that open surgery for infundibular stenosis, calculi in calyceal diverticula (particularly in an anterior calyx), skeleton deformities, fixed hip and leg contractures and deformities, associated comorbidities, concomitant open surgery, kidney inferior pole renal (partial nephrectomy), non-functional kidney (nephrectomy), and ectopic kidney calculi, in which percutaneous access and ECWL may be difficult or impossible ${ }^{7}(\mathrm{D})$.

For large and complex intrarenal calculi, the kidney can be opened in order to access the complete collecting system by means of anatrophic nephrolithotomy. This is currently an unusual technique but a valid approach for managing large staghorn calculi resistant to minimally invasive approaches and in patients with comorbidities such as chronic obstructive pulmonary disease ${ }^{8}(\mathrm{C})$. Anatrophic nephrolithotomy in cases of complex and large volume calculi can present a rate of calculus-free patients, in a single session, better than that obtained from percutaneous kidney lithotripsy, with a lower total treatment cost, but with greater loss of kidney function $\left({ }^{9}\right)$. With AN, it is possible to achieve a calculus-free rate between $80 \%$ and $100 \%$, without many secondary interventions ${ }^{10}(\mathrm{C})$. The use of laparoscopy ${ }^{8.11}(\mathrm{C})$ and robotic assistance ${ }^{12}(\mathrm{C})$ allows a minimal postoperative hospital stay, with faster recovery and results comparable to those from the gold-standard open surgery.

In some patients with voluminous or complex calculi, the endoscopic treatment by percutaneous antegrade ureterorenoscopy can allow for faster elimination of the calculi since larger and more efficient instruments can be used $\left({ }^{13}\right)$. The benefits and increased invasiveness with a risk of complications that accompany the use of percutaneous access must be taken into account in the decision-making. Ureterolithotomy can also be considered as an alternative therapy in these rare clinical scenarios. Both laparoscopic ${ }^{14}(\mathrm{~A})$ and robot-assisted ureterolithotomy provide equivalent results to open surgery, but with reduced morbidity ${ }^{15}(\mathrm{D})$.

Nephrectomy may be necessary in patients with renal calculi and severe infection, such as in cases of xanthogranulomatous pyelonephritis. Although the laparoscopic access route is preferred, conversion to open surgery may be necessary in approximately $7 \%$ of the cases due to intense perirenal adherence ${ }^{16}(B)$.

There are several options for treating urinary lithiasis, with the following calculus-free rates described: extracorporeal shock wave lithotripsy - 75-100\%; transureteroscopic cystolithotripsy - 63-100\%, percutaneous cystolithotripsy - 89-100\%; and open surgery -100\%. The use of percutaneous access presents lower morbidity, with similar results to those from transurethral treatment, while the extracorporeal lithotripsy provides the lowest rates of calculi elimination and is reserved for patients at high surgical risk( ${ }^{17}(\mathrm{~A})$. Open cystolithotomy may be indicated in cases of large-volume or hard calculi resistant to the endoscopic approach, abnormal anatomy to allow safe access, concomitant open procedure (such as prostatectomy or diverticulectomy), or in cases in which it is impossible to transpose the urethra ${ }^{18-20}(\mathrm{C})$. 


\section{Open surgery in pediatric patients}

In children, most calculi can be controlled by using the ECWL and endoscopic techniques ${ }^{21}(\mathrm{C})$. The indications for open surgery include: failed primary therapy for the removal of the calculi; very young children with complex calculi; congenital obstruction that requires simultaneous surgical correction; severe orthopedic deformities that limit the positioning for endoscopic procedures; and abnormal position of the kidney ${ }^{22}(\mathrm{D})$. Open surgery can be replaced by laparoscopic procedures $^{23.24}(\mathrm{C})$. Open surgery was considered the gold-standard treatment for pediatric bladder lithiasis for a long time, providing excellent rates and success. The development of smaller equipment, associated with the increased experience of endourologists with minimally invasive procedures, has led to greater use of endoscopic approaches for treating bladder calculi in pediatric patients.

\section{Recommendation}

In adult patients:

- Laparoscopic or open surgery is indicated in the rare cases in which lithotripsy by shock waves, ureterorenoscopy (flexible), and percutaneous nephrolithotomy fail or are unlikely to succeed (D).

- Both laparoscopic (A) and robot-assisted ureterolithotomy provide equivalent results to those of open surgery, but with reduced morbidity(D).

- Open cystolithotomy may be indicated in cases of large-volume or hard calculi resistant to the endoscopic approach, abnormal anatomy to allow safe access, concomitant open procedure (such as prostatectomy or diverticulectomy), or in cases in which it is impossible to transpose the urethra (C).

- In bladder lithiasis, the use of percutaneous access presents lower morbidity, with similar results to those from transurethral treatment, while the extracorporeal lithotripsy provides the lowest rates of calculi elimination and is reserved for patients at high surgical risk (A).

In pediatric patients:

- The indications for open surgery include: failed primary endoscopic therapy for the removal of the calculi; very young children with complex calculi; congenital obstruction that requires simultaneous surgical correction; severe orthopedic deformities that limit the positioning for endoscopic procedures; and abnormal position of the kidney (D).

- Open surgery can be replaced by laparoscopic procedures in pediatric patients (C).

\section{ANNEX I}

\section{Clinical question}

What are the main indications for open surgery in urolithiasis?

\section{Eligibility criteria}

The main reasons for exclusion were: not an answer to PICO and intermediary outcomes.

Narrative reviews, case studies, series of cases, studies with presentations of preliminary results were, initially, excluded.

Since we are discussing treatment options, we used a controlled randomized clinical trial.

\section{Search for papers}

Database

The scientific information databases consulted were Medline (via PubMed), Central (Cochrane), and manual search.

\section{Identification of descriptors}

\begin{tabular}{|l|l|}
\hline $\mathbf{P}$ & $\begin{array}{l}\text { Patients in whom the only option for urolithiasis } \\
\text { treatment is open surgery }\end{array}$ \\
\hline I & Open surgery for urolithiasis \\
\hline C & Failure with other procedures in therapy \\
\hline O & - \\
\hline
\end{tabular}

\section{Search strategy}

Searches were conducted until March 30, 2018.

- \#1 (urolithiasis OR urinary lithiasis OR nephrolithiasis OR kidney calculi OR ureterolithiasis OR ureteral calculi OR urinary calculi) AND (lithotripsies OR lithotripsy OR litholapaxy OR litholapaxies OR percutaneous ultrasonic lithotripsy OR extracorporeal shockwave lithotripsy OR ESWL OR noninvasive litholapaxy OR ureteroscopy OR ureteroscopic OR open surgery) AND therapy/broad[filter]

- \#2 (urolithiasis OR urinary lithiasis OR nephrolithiasis OR kidney calculi OR ureterolithiasis OR ureteral calculi OR urinary calculi) AND (anatrophic nephrolithotomy) AND therapy/broad[filter]

- \#3 (urinary bladder calculi OR Bladder Stones OR Urinary Bladder Stones OR Vesical Calculi OR vesical calculus OR Bladder Calculi OR Bladder Calculus OR Cystolith) AND therapy/broad[filter]

- Manual search - References of references, reviews and guidelines. 


\section{Critical evaluation}

Relevance - Clinical importance

This Guideline was prepared by means of a clinically relevant question in order to gather information in medicine to standardize approaches and assist in decision-making.

\section{Reliability - Internal validity}

The selection of the studies and the evaluation of the titles and abstracts obtained from the search strategy in the databases consulted were independently and blindly conducted, in total accordance with the inclusion and exclusion criteria. Finally, studies with potential relevance were separated. When the title and the summary were not enlightening, we sought for the full article. Only studies with texts available in its entirety were considered for critical evaluation.

We included studies available in Portuguese, English, Spanish, French, or Italian.

\section{Results application - External validity}

The level of scientific evidence was classified by type of study according to Oxford ${ }^{25}$ (Table 1).

\section{TABLE 01. GRADES FOR RECOMMENDATION AND} LEVELS OF EVIDENCE

\begin{tabular}{|l|}
\hline A: Experimental or observational studies of higher consistency. \\
\hline B: Experimental or observational studies of lower consistency. \\
\hline C: Uncontrolled studies/case reports. \\
\hline $\begin{array}{l}\text { D: Opinion deprived of critical evaluation, based on consensus, } \\
\text { physiological studies, or animal models. }\end{array}$ \\
\hline
\end{tabular}

The selected evidence was defined as a randomized controlled clinical trial (RCT) and submitted to an appropriate critical evaluation checklist (Table 2). The critical evaluation of RCTs allows to classify them according to the Jadad score ${ }^{26}$, considering Jadad trials $<$ three (3) as inconsistent (grade B) and those with score $\geq$ three (3) consistent (grade A), and according to the Grade $^{27}$ score (strong or moderate evidence).

When the evidence selected was defined as a comparative study (observational cohorts, or non-randomized clinical trial), it was subjected to an adequate critical assessment checklist (Table 3), allowing for the classification of the study, according to the Newcastle-Ottawa Scale ${ }^{28}$, which considered consistent cohort studies with scores $\geq 6$, and inconsistent $<6$.

TABLE 2. PROCESS FOR CRITICAL EVALUATION OF RANDOMIZED CONTROLLED CLINICAL TRIALS

\begin{tabular}{l|l}
\hline $\begin{array}{l}\text { Study data } \\
\text { Reference, study design, JA- } \\
\text { DAD, level of evidence }\end{array}$ & $\begin{array}{l}\text { Sample size calculation } \\
\text { Estimated differences, power, } \\
\text { significance level, the total num- } \\
\text { ber of patients }\end{array}$ \\
\hline $\begin{array}{l}\text { Patient selection } \\
\text { Inclusion and exclusion criteria }\end{array}$ & $\begin{array}{l}\text { Patients } \\
\text { recruited, randomized, prognos- } \\
\text { tic differences }\end{array}$ \\
\hline $\begin{array}{l}\text { Randomization } \\
\text { Description and blinded allo- } \\
\text { cation }\end{array}$ & $\begin{array}{l}\text { Patient follow-up, time, losses, } \\
\text { migration }\end{array}$ \\
\hline $\begin{array}{l}\text { Treatment protocol } \\
\text { Intervention, control and } \\
\text { blinding }\end{array}$ & $\begin{array}{l}\text { Analysis } \\
\text { Intention to treat, analyzed } \\
\text { intervention and control }\end{array}$ \\
\hline $\begin{array}{l}\text { Outcomes considered } \\
\text { Primary, secondary, mea- } \\
\text { surement instrument for the } \\
\text { outcome of interest }\end{array}$ & $\begin{array}{l}\text { Results } \\
\text { Benefits or harmful effects in ab- } \\
\text { solute data, benefits or harmful } \\
\text { effects on average }\end{array}$ \\
\hline
\end{tabular}

\section{Method of extraction and result analysis}

For results with available evidence, the population, intervention, outcomes, presence or absence of benefits and/or harmful events, and controversy must be specifically defined whenever possible.

The results will be presented preferably in absolute data, absolute risk, the number needed to treat (NNT) or number needed to harm (NNH) and, eventually, in mean and standard deviation values (Table 4).

TABLE 4. SPREADSHEET USED FOR DESCRIBING AND PRESENTING THE RESULTS OF EACH STUDY

\begin{tabular}{|l|}
\hline Evidence included \\
\hline Study design \\
\hline Selected population \\
\hline Follow-up time \\
\hline Outcomes considered \\
\hline Expression of results: percentage, risk, odds, hazard ratio, mean \\
\hline
\end{tabular}

TABLE 3. PROCESS FOR CRITICAL EVALUATION OF COHORT STUDIES

\begin{tabular}{|l|l|l|l|l|l|l|}
\hline $\begin{array}{l}\text { Representativeness } \\
\text { of the exposed and } \\
\text { selection of } \\
\text { non-exposed (max. } \\
2 \text { points) }\end{array}$ & $\begin{array}{l}\text { Definition } \\
\text { of exposure } \\
\text { (max. 1 point) }\end{array}$ & $\begin{array}{l}\text { Demonstrating that the } \\
\text { outcome of Interest was } \\
\text { not present at the begin- } \\
\text { ning of the study (max. } \\
\text { 1 point }\end{array}$ & $\begin{array}{l}\text { Comparability on } \\
\text { the basis of the } \\
\text { design or analysis } \\
\text { (max. 2 points) }\end{array}$ & $\begin{array}{l}\text { Outcome } \\
\text { assessment } \\
\text { (max. 1 point) }\end{array}$ & $\begin{array}{l}\text { Adequate } \\
\text { follow-up time } \\
\text { (max. 2 points) }\end{array}$ & $\begin{array}{l}\text { Score and level } \\
\text { of } \\
\text { evidence }\end{array}$ \\
\end{tabular}




\section{Results}

TABLE 5. NUMBER OF PAPERS RETRIEVED BY USING THE SEARCH STRATEGY IN EACH OF THE SCIENTIFIC DATABASES

\begin{tabular}{l|l}
\hline DATABASE & NUMBER OF PAPERS \\
\hline Primary & 4457 \\
\hline PubMed/Medline &
\end{tabular}

\section{Application of evidence - Recommendation}

The recommendations will be elaborated by the authors of the review, with the initial characteristic of synthesis of evidence, being subject to validation by all authors who participated in creating the Guideline.

The global synthesis will be based on the evidence described. Its strength will be estimated (Oxford ${ }^{25}$ / Grade $^{27}$ ) as $1 \mathrm{~b}$ and $1 \mathrm{c}$ (grade A) or strong, and as 2a, $2 \mathrm{~b}$ and $2 \mathrm{c}$ (grade $\mathrm{B}$ ) or moderate weak, or very weak.

\section{Conflict of interest}

There is no conflict of interest related to this review that can be declared by any of the authors.

\section{REFERENCES}

1. Chaussy C, Brendel W, Schmiedt E. Extracorporeally induced destruction of kidney stones by shock waves. Lancet 1980 13;2:1265-8. PMID: 6108446

1. Lingeman, J. E., Matlaga, B. R. \& Evan, A. P. in Campbell-Walsh Urology $9^{\text {th }}$ edn Ch. 44 (eds Wein, A. .., Kavoussi. L. R., Novick, A, C., Partin, A. W. \& Peters, C. A.) (Saunders, 2007).

2. Singal R, Dhar S. Retroperitoneal laparoscopic pyelolithotomy in renal pelvic stone versus open surgery - a comparative study. Clujul Med. 2018;91(1):8591. PMID: 29440956

3. Assimos D, Krambeck A, Miller NL, Monga M, Murad MH, Nelson CP, et al. Surgical Management of Stones: American Urological Association/Endourological Society Guideline, PART I. J Urol 2016;196:1153-60. PMID: 27238616.

4. Preminger GM, Assimos DG, Lingeman JE, Nakada SY, Pearle MS, Wolf JS Jr; AUA Nephrolithiasis Guideline Panel). Chapter 1: AUA guideline on management of staghorn calculi: diagnosis and treatment recommendations. J Urol 2005;173:1991-2000. PMID: 15879803.

5. Turk C, Neisius A, Petzôik A, et al: EAU Guidelines on Urolithiasis. 2017. Available at: https://uroweb.org/guideline/urolithiasis.

6. Turk, T. Knoll, A. Petrik, K. Sarica, A. Skolarikos, M. Straub, C. Seitz; European Association of Urology; Guidelines on urolithiasis; 2013. Available at: http:// portaldaurologia.org.br/medicos/wp-content/uploads/2017/06/369.pdf.

7. Simforoosh N, Aminsharifi A, Tabibi A, Noor-Alizadeh A, Zand S, Radfar $\mathrm{MH}$, et al. Laparoscopic anatrophic nephrolithotomy for managing large staghorn calculi. BJU Int. 2008;101(10):1293-96

8. Aminsharifi A, Irani D, Masoumi M, Goshtasbi B, Aminsharifi A, Mohamadian R.The management of large staghorn renal stones by percutaneous versus laparoscopic versus open nephrolithotomy: a comparative analysis of clinical efficacy and functional outcome. Urolithiasis. 2016 Nov;44(6):551557. Epub 2016 Mar 31. PMID: 27032961

9. Keshavamurthy R, Karthikeyan VS, Mallya A, Sreenivas J, Nelivig GG, Kamath AJ. Anatrophic Nephrolithotomy in the Management of Large Staghorn Calculi - A Single Centre Experience. J Clin Diagn Res 2017;11:PC01-PC04. PMID: 28658843.

10. Deger S, Tuellmann M, Schoenberger B, Winkelmann B, Peters R, Loening SA. Laparoscopic anatrophicnephrolithotomy. Scand | Urol Nephrol. 2004;38(3):263-65.

11. King SA, Klaassen Z, Madi R. Robot-assisted anatrophic nephrolithotomy: description of technique and early results. J Endourol. 2014;28:325-9. PMID: 24147980

12. Basiri A, Simforoosh N, Ziaee A, Shayaninasab H, Moghaddam SM, Zare S Retrograde, antegrade, and laparoscopic approaches for the management of large, proximal ureteral stones: a randomized clinical trial. J Endourol 2008;22:2677-80. PMID: 19025388

13. Lopes Neto AC, Korkes F, Silva JL 2 nd , Amarante RD, Mattos MH, Tobias-Machado $\mathrm{M}$, et al. Prospective randomized study of treatment of large

proximal ureteral stones: extracorporeal shock wave lithotripsy versus ureterolithotripsy versus laparoscopy. | Urol 2012;187:164-8. PMID: 22100003.

14. Assimos D, Krambeck A, Miller NL, Monga M, Murad MH, Nelson CP, et al. Surgical Management of Stones: American Urological Association/Endourological Society Guideline, PART II. J Urol 2016;196:1161-9. PMID: 27238615.

15. Angerri $O, L \sqrt{ } \geq$ pez $\mid M, S V^{\circ}$ nchez-Martin $F$, MillV ${ }^{\circ} n$-Rodriguez $F$, Rosales $A$, Villavicencio H. Simple Laparoscopic Nephrectomy in Stone Disease: Not Always Simple. J Endourol. 2016 Oct;30(10):1095-1098. PMID:27479686.

16. Torricelli FC, Mazzucchi E, Danilovic A, Coelho RF, Srougi M. Surgical management of bladder stones: literature review. Rev Col Bras Cir 2013;40(3):227-33. PMID: 23912371

17. Bhatia V, Biyani CS. Vesicallithiasis: open surgery versus cystolithotripsy versus extracorporeal shock wave therapy. J Urol 1994;151:660-2.

18. Franzoni DF, Decter RM. Percutaneous vesicolithotomy: an alternative to open bladder surgery in patients with an impassable or surgically ablated urethra. J Urol 1999; 162:777-8.

19. Richter S, Ringel A, Sluzker D. Combined cystolithotomy and transu- rethral resection of prostate: best mana- gement of infravesical obstruction and massive or multiple bladder stones. Urology 2002;59:688-91.

20. Muslumanoglu AY, Tefekli A, Sarilar O, Binbay M, Altunrende F, Ozkuvanci $U$. Extracorporeal shock wave lithotripsy as first line treatment alternative for urinary tract stones in children: a large scale retrospective analysis. J Urol 2003;170:2405-8. PMID: 14634438

21. Straub M, Gschwend ), Zorn C. Pediatric urolithiasis: the current surgical management. Pediatr Nephrol 2010;25:1239-44. PMID: 20130924

22. Casale P, Grady RW, Joyner BD, Zeltser IS, Kuo RL, Mitchell ME. Transperitoneal laparoscopic pyelolithotomy after failed percutaneous access in the pediatric patient. J Urol 2004;172:680-3; discussion 683. PMID: 15247760.

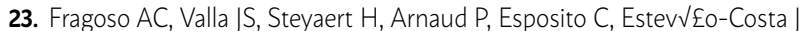
Minimal access surgery in the management of pediatric urolithiasis. J Pediatr Urol 2009;5:42-6. PMID: 18805739.

24. Levels of Evidence and Grades of Recommendations - Oxford Centre for Evidence Based Medicine. Disponível em URL: http://cebm.jr2.ox.ac.uk/ docs/ old_levels. Htm

25. Jadad AR, Moore RA, Carroll D, Jenkinson C, Reynolds D|, Gavaghan D|, et al. Assessing the quality of reports of randomized clinical trials: is blinding necessary? Control Clin Trials 1996; 17:1-12.

26. Goldet G, Howick J. Understanding GRADE: an introduction. J Evid Based Med 2013; 6:50-4.

27. Wells G, Shea B, O'Connell D, Robertson |, Peterson I, Welch V, et al. The Newcastle-Ottawa Scale (NOS) for assessing the quality of nonrandomised studies in meta-analyses.Disponível em: http://www.ohri.ca/programs/ clinical_epidemiology/oxford.asp 